\title{
Rapid-Onset Hyponatremia Induced by Duloxetine in a Middle-Aged Male with Depression and Somatic Symptoms
}

\author{
Jung-Seok Choi ${ }^{1,2}$, Hae Woo Lee ${ }^{1,2}$, Jun Young Lee ${ }^{1,2}$ and Hee Yeon Jung ${ }^{1,2} \bowtie$ \\ ${ }^{1}$ Department of Psychiatry, SMG-SNU Boramae Medical Center, Seoul, Korea \\ ${ }^{2}$ Department of Psychiatry and Behavioral Science, Seoul National University College of Medicine, Seoul, Korea
}

Duloxetine is a relatively balanced selective serotonin and noradrenaline reuptake inhibitor. We report a case of hyponatremia induced by duloxetine developed rapidly after starting the medication in a middle-aged male with multiple somatic symptoms and depression. Two days after discontinuation of duloxetine and management with hypertonic saline as well as fluid restriction, the serum sodium level normalized. The patient had two risk factors for developing hyponatremia, such as severe body weight loss and pneumonia. Therefore, when treating patients with depression and somatic symptoms, especially with risk factors for developing hyponatremia, close monitoring for clinical and laboratory evidence of hyponatremia may be essential.

Psychiatry Investig 2012;9:83-84

Key Words Duloxetine, Hyponatremia, Middle-aged male, Somatic symptoms, Depression.

\section{INTRODUCTION}

Hyponatremia is defined as a decrease in the serum sodium concentration to a level less than $134 \mathrm{mmol} / \mathrm{L}$. Hyponatremia is a reported complication of treatment with antidepressant drugs such as selective serotonin reuptake inhibitors (SSRIs), including fluoxetine and sertraline, and the dual-action antidepressant venlafaxine. ${ }^{1,2}$

Duloxetine is a relatively balanced selective serotonin and noradrenaline reuptake inhibitor (SNRI), which is approved for the treatment of major depressive disorder, generalized anxiety disorder, and diabetic peripheral neuropathic pain. The most frequently reported adverse events with duloxetine include nausea $(20 \%)$, dry mouth (16\%), fatigue (11\%), dizziness (11\%), constipation (11\%), somnolence (8\%), decreased appetite (6\%), and increased sweating (5\%). In rare cases, hyponatremia induced by duloxetine has been reported in patients with depression ${ }^{4-6}$ and neuropathic pain. ${ }^{7}$ However, most cases have involved elderly female patients ( 66 or 85 years old);, ${ }^{5,6}$ there is no report of hy-

Received: May 24, 2011 Revised: August 3, 2011

Accepted: August 15, 2011 Available online: January 18, 2012

$\triangle$ Correspondence: Hee Yeon Jung, MD, PhD

Department of Psychiatry, SMG-SNU Boramae Medical Center, 39 Boramaegil, Dongjak-gu, Seoul 156-707, Korea

Tel: +82-2-870-2461, Fax: +82-2-870-3866, E-mail: hyjung@snu.ac.kr

(a) This is an Open Access article distributed under the terms of the Creative Commons Attribution Non-Commercial License (http://creativecommons.org/licenses/bync/3.0) which permits unrestricted non-commercial use, distribution, and reproduction in any medium, provided the original work is properly cited. ponatremia associated with duloxetine in middle-aged males with depression as well as multiple somatic symptoms.

\section{CASE}

A 58-year-old male patient was admitted with multiple somatic symptoms: chiefly, a tingling sense and pain in all four extremities and a foreign body sensation in the throat. In addition, he showed anxiety, depressed mood, sleep disturbance, decreased oral intake, and weight loss. To evaluate his somatic symptoms, he had undergone nerve conduction studies, electromyography, neck computed tomography (CT), abdomen/chest CT, brain magnetic resonance imaging (MRI), and blood tests. No abnormalities were found. Immediately after this evaluation, he developed a high fever and leukocytosis. Pneumonia was diagnosed based on a physical examination and chest x-ray. After administering antibiotics (amikacin sulfate), his vital signs and leukocytosis normalized. Then, on hospital day 5, duloxetine $30 \mathrm{mg}$ daily was initiated for the multiple somatic symptoms and depressive symptoms. His serum sodium level on that day was $135.1 \mathrm{mmol} / \mathrm{L}$. The serum sodium the next day was $130 \mathrm{mmol} /$ L. Three days after initiating the duloxetine, his serum sodium decreased to $127 \mathrm{mmol} / \mathrm{L}$. Since his presenting somatic symptoms had not changed and he did not show any other adverse events, the dose of duloxetine was increased to $60 \mathrm{mg}$ daily 5 days after initiating the duloxetine. The next day, the serum sodium level had decreased to $122 \mathrm{mmol} / \mathrm{L}$. The serum osmolari- 
ty was $263 \mathrm{mOsm} / \mathrm{kg}$, and the urine osmolarity was $394 \mathrm{mOsm} /$ $\mathrm{kg}$, with a urine sodium of $81.4 \mathrm{mmol} / \mathrm{L}$. Thyroid function tests and the cortisol level were normal. The syndrome of inappropriate antidiuretic hormone (SIADH) was diagnosed based on the presence of hyponatremia, hypo-osmolarity, increased urine osmolarity, and increased urine sodium level. The duloxetine was discontinued and the patient was managed with hypertonic saline and fluid restriction. Two days after discontinuing the duloxetine, the serum sodium level had normalized to 135.4 $\mathrm{mmol} / \mathrm{L}$.

\section{DISCUSSION}

Our patient developed hyponatremia within 1 week of administering duloxetine for multiple somatic symptoms and depressive symptoms. The cause of the hyponatremia was considered to be SIADH. However, the mechanism of SIADH associated with an SSRI or SNRI is unclear. Roxanas ${ }^{8}$ postulated that hyponatremia associated with an SSRI might be related to the serotonergic stimulation of antidiuretic hormone (ADH) production. Arinzon et al. ${ }^{9}$ also suggested that SSRI-induced SIADH is multifactorial, including an increase in the secretion of $\mathrm{ADH}$ centrally, augmentation of the effect of $\mathrm{ADH}$ in the renal medulla, a resetting of the osmostat that lowers the threshold for secretion, and an interaction with other drugs.

In this case, there were several distinct findings associated with the hyponatremia induced by duloxetine. First, the patient was male and was not elderly. Previous reports of duloxetineinduced hyponatremia have been in elderly females. ${ }^{5-7}$ In addition, hyponatremia from SSRI use has been reported in elderly females predominantly. ${ }^{8-10}$ Second, the hyponatremia began 1 day after duloxetine administration. The hyponatremia related to SSRI use developed 2 to 3 weeks following the start of the drug, ${ }^{11,12}$ while the hyponatremia induced by duloxetine developed more rapidly. Previous reports described hyponatremia developing after 2 or 3 days of duloxetine therapy, which concurs with our report. ${ }^{7,13}$ Third, the patient had two risk factors for developing hyponatremia: lower body weight and pneumonia. The risk factors for hyponatremia include older age, female, history of hyponatremia, lower body mass index (BMI), use of thiazide diuretics, lower baseline serum sodium level $(<138$ $\mathrm{mmol} / \mathrm{L}$ ), and significant comorbidities. ${ }^{11,14-16}$ Especially, Fabian et al. ${ }^{11}$ suggested that a lower BMI was a significant risk factor for developing hyponatremia associated with SSRI use. Our patient had a BMI of 15.2 on admission. Furthermore, the patient had pneumonia before beginning the duloxetine ther- apy. These factors may have precipitated the duloxetine-induced hyponatremia.

In summary, hyponatremia induced by duloxetine developed rapidly after starting the medication in a middle-aged male with multiple somatic symptoms and depression. Two risk factors - severe body weight loss and pneumonia - may have made him more vulnerable to developing hyponatremia. Therefore, when treating patients with depression and somatic symptoms, especially with risk factors for developing hyponatremia, close monitoring for clinical and laboratory evidence of hyponatremia is essential.

\section{REFERENCES}

1. Movig KL, Leufkens HG, Lenderink AW, Egberts AC. Serotonergic antidepressants associated with an increased risk for hyponatraemia in the elderly. Eur J Clin Pharmacol 2002;58:143-148.

2. Movig KL, Leufkens HG, Lenderink AW, van den Akker VG, Hodiamont PP, Goldschmidt HM, et al. Association between antidepressant drug use and hyponatraemia: a case-control study. Br J Clin Pharmacol 2002;53:363-369.

3. Nemeroff CB, Schatzberg AF, Goldstein DJ, Detke MJ, Mallinckrodt C, $\mathrm{Lu}$ Y, et al. Duloxetine for the treatment of major depressive disorder. Psychopharmacol Bull 2002;36:106-132.

4. Krüger S, Lindstaedt M. Duloxetine and hyponatremia: a report of 5 cases. J Clin Psychopharmacol 2007;27:101-104.

5. Dirks AC, van Hyfte DM. Recurrent hyponatremia after substitution of citalopram with duloxetine. J Clin Psychopharmacol 2007;27:313.

6. 6. Stovall R, Brahm NC, Crosby KM. Recurrent episodes of serotoninreuptake inhibitor-mediated hyponatremia in an elderly patient. Consult Pharm 2009;24:765-768.

7. Safdieh JE, Rudominer R. A case of hyponatremia induced by duloxetine. J Clin Psychopharmacol 2006;26:675-676.

8. Roxanas MG. Mirtazapine-induced hyponatraemia. Med J Aust 2003; 179:453-454.

9. Arinzon ZH, Lehman YA, Fidelman ZG, Krasnyansky II. Delayed recurrent SIADH associated with SSRIs. Ann Pharmacother 2002;36:11751177.

10. Wright SK, Schroeter S. Hyponatremia as a complication of selective serotonin reuptake inhibitors. J Am Acad Nurse Pract 2008;20:47-51.

11. Fabian TJ, Amico JA, Kroboth PD, Mulsant BH, Corey SE, Begley AE, et al. Paroxetine-induced hyponatremia in older adults: a 12-week prospective study. Arch Intern Med 2004;164:327-332.

12. Finfgeld DL. SSRI-related hyponatremia among aging adults. J Psychosoc Nurs Ment Health Serv 2003;41:12-16.

13. Maramattom BV. Duloxetine-induced syndrome of inappropriate antidiuretic hormone secretion and seizures. Neurology 2006;66:773-774.

14. Bowen PD. Use of selective serotonin reuptake inhibitors in the treatment of depression in older adults: identifying and managing potential risk for hyponatremia. Geriatr Nurs 2009;30:85-89.

15. Kirby D, Ames D. Hyponatraemia and selective serotonin re-uptake inhibitors in elderly patients. Int J Geriatr Psychiatry 2001;16:484-493.

16. Kirby D, Harrigan S, Ames D. Hyponatraemia in elderly psychiatric patients treated with Selective Serotonin Reuptake Inhibitors and venlafaxine: a retrospective controlled study in an inpatient unit. Int J Geriatr Psychiatry 2002;17:231-237. 